\title{
LA CONSTRUCGIÓN DEL PALACIO DEL AYUNTAMIENTO. NOTAS HISTÓRICAS
}

\author{
Francisco Emanuel Vidargas \\ A Guillermo Porras Muñoz \\ In Memoriam
}

Habiéndose consumado la conquista del señorío mexica y destruida la ciudad según la consigna de Hernán Cortés, se erigió con rapidez sobre los cimientos de la ciudad antigua la nueva sede del gobierno español en tierras americanas, con el fin de producir en la población nativa gran temor, al ver que "los conquistadores estaban allí para quedarse". ${ }^{1} \mathrm{El}$ alarife Alonso García Bravo, auxiliado por Bernardo Vázquez de Tapia, realizó la nueva traza; el urbanista español inició los trabajos en el año 1523, dado que el Cabildo fue trasladado a la capital desde Coyoacán, donde pudo celebrar sus primeras reuniones en $1524 .{ }^{2}$ Para que la corporación realizara su cambio de sede, se construyeron antes las fortalezas o atarazanas "para tener seguros y disponibles los bergantines de la Conquista". ${ }^{3}$ El régimen municipal se instaló el 8 de marzo de 1524 en las casas de Cortés, establecidas sobre el antiguo palacio de Axayácatl, y lo integraron Francisco de las Casas, alcalde mayor, Juan de Ortega y Bernardino Vázquez de Tapia, alcaldes ordinarios, y los regidores Gonzalo de Ocampo, Rodrigo de Paz, Juan de Hinojosa, Diego de Soto, Alonso de Jaramillo, Cristóbal Flores y Alonso de Mendoza. El escribano fue Francisco de Orduño, y el mayordomo Fernando López. ${ }^{4}$ Ningún solar en la ciudad era edificado sin que primero fuera medido y trazado por Alonso García Bravo ${ }^{5}$ y así, poco a

\footnotetext{
I Guillermo Porras Muñoz: el Gobiemo de la ciudad de México en el siglo xvI, México, Universidad Nacional Autónoma de México, Instituto de Investigaciones Históricas, 1982 (Serie de Historia Novohispana, 31), p 29

${ }^{2}$ Manuel Toussaint: Información de méritos y servicios de Alonso García Bravo, alarife que trazó la Ciudad de México, México, Universidad Nacional Autónoma de México, Instituto de Investigaciones Estéticas, 1956 (Estudios y Fuentes del Arte en México, III), p 11.

"José Luis Martínez: "Construcción de la nueva ciudad", Artes de México, nueva época, núm. 1 (México, otoño de 1988), p. 35

${ }^{4}$ Ernesto de la Torre Villar, Ramiro Navarro de Anda: Historia de México I (Época Prehispánica y Colonial), México, Mc Graw-Hill, 1987

${ }^{5}$ Acta de Cabildo: 14 de enero de 1527
} 
poco en el centro de la nueva traza, reservado para toda actividad pública, "quedaron los solares en los que en épocas sucesivas fueron levantándose los edificios que albergaron a las instrucciones que dirigían la vida de la naciente colonia" ${ }^{6}$ Por la misma razón es muy probable que García Bravo designara el lugar que le correspondería al Cabildo en seis solares de la plaza. Es hasta 1527 cuando se inició la construcción de las casas consistoriales o de Cabildo, primera sede del gobierno de la ciudad y fueron ubicadas en el costado sur de la Plaza Mayor, en los terrenos expropiados al español Alonso de Estrada por orden de la Corona. El proyecto inicial incluía "una sección para el consejo, una prisión y locales para el mercado municipal de carne" ${ }^{7}$ La construcción se inició bajo la supervisión del alarife maestre Martín de Sepúlveda y de Juan Rodríguez de Salas, quienes antes habían trabajado en la edificación de las casas de Cortés. El 28 de marzo de 1530 el Cabildo comisionó a Francisco de Santacruz, regidor, para que "entienda y trace la casa y corredor que serán para el Cabildo". Los trabajos se realizaban muy lentamente hasta que la Audiencia decidió acelerarlos ordenando la compra, el 7 de noviembre de 1531, de los propios y rentas de la ciudad; los materiales necesarios para la edificación, habiendo quedado comprometidos sesenta indios para trabajar diariamente a lo largo de tres meses, y lograr así la pronta terminación de las casas. Diez días después se encomendó al regidor Santacruz para que se llevara a cabo el traslado de las piedras que formaron parte de edificaciones indígenas que se encontraban en la plaza y se utilizaran en las portadas de la sede del gobierno citadino. ${ }^{9}$ Así se continuaron las obras hasta que en mayo de 1532 fueron entregadas las edificaciones, ya concluidas, realizándose el día $10 \mathrm{del}$ mismo mes la primera reunión del Cabildo en su nueva casa. ${ }^{10}$

Quizás por la premura de su terminación, el edificio reveló muy pronto defectos en su construcción, motivando esto que el 19 de mayo de 1533 se pidiera al maestro de obras Juan Dentrambas Aguas, que diera fe de la mala calidad de la piedra utilizada en la edificación de los pilares ${ }^{11} \mathrm{~A}$ finales del mismo año se comisionó al alcalde Ruy González y al regidor Lope de

\footnotetext{
${ }^{6}$ María del Carmen León Cazares: La Plaza Mayor de la Cindad de México en la vida cotidiana de sus habitantes (Siglos XVI y XVII), presentación de Valentín Molina Piñeiro y dos palabras previas de Beatriz Ruiz-Gaytán, México, Instituto de Estudios y Documentos Históricos, A. C, 1982 (Seric Estudios, 5).

${ }^{7}$ George Kubler: Arquitectura mexicana del siglo XvI, México, Fondo de Cultura Económica, 1983 , p. 220.

${ }^{8}$ Acta de Cabildo: 28 de marzo de 1530

${ }^{9}$ Idem, 7 de noviembre de 1531 .

${ }_{11}^{10}$ María del Carmen León Cazares: op cit., p. 91.

${ }^{11}$ Acta de Cabildo: 19 de mayo de 1533
} 
Samaniego para que compraran a Rodrigo de Albornoz, Juan de Oñate, Pedro García y otras personas, las piedras necesarias para las mejoras que necesitaba el inmueble. ${ }^{12} \mathrm{El}$ día 22 de diciembre se ordenó también la difusión de un pregón entre la población para que los vecinos de Ixtapalapa no extrajeran piedras de la cantera que había sido cortada por los indios de la villa, ya que serían utilizadas en la reconstrucción. ${ }^{13}$ Como era costumbre en la época, las construcciones se realizaban "en todo a costa de los indios, quienes debían traer, y luego labrar, piedras, maderas y los demás materiales de construcción, y aun proveer su propia alimentación"; ; los españoles únicamente proyectaban las obras y las dirigían. Las casas consistoriales se habían instalado con sus dependencias en los solares ubicados a un costado de la acequia; el puente donde se daban los pregones de aviso de los diversos acuerdos y reglamentos de la ciudad se encontraba frente al inmueble; ahí "desembarcaban las canoas de los indios cargadas de víveres, se celebraban las almonedas públicas y los vigilados oficiales reales pesaban y sellaban las barras de la plata para cobrar el quinto de su majestad". ${ }^{15}$ Finalmente es en 1536 cuando son terminados los arreglos del edificio; a partir de ese momento, y hasta fechas cercanas a nosotros, el palacio del Ayuntamiento sufrirá múltiples reformas a la llegada de cada nuevo regidor y según las necesidades y el gusto de la época imperante.

Desde 1535 se encontraba asentado en la Ciudad de México el primer virrey de la Nueva España, don Antonio de Mendoza. La traza de la ciudad se realizó bajo sus órdenes y su gran visión urbanística. Sus consideraciones y propósitos fueron de carácter urbano, político, científico y utópico, bajo las bases del Tratado de arquitectura de León Battista Alberti, logrando que la metrópoli fuera uno de los ejemplos más notables en el urbanismo de Occidente. ${ }^{16}$

Hacia 1539 se registran las primeras modificaciones arquitectónicas en el inmueble, aumentando los locales que se encontraban en la planta baja, de acuerdo con las exigencias de las Cédulas Reales y las directrices urbanas del momento. En 1554 Francisco Cervantes de Salazar describía al palacio como una casa que presentaba portales bajos que "adornan y enriquecen a la plaza"; además contenía en su parte superior a la sala de Cabildos "famosa por su galería de columnas y arcos de piedra con su vista a la plaza". ${ }^{17}$

${ }^{12}$ Idem, 17 de noviembre de 1593 .

${ }^{13}$ Idem, 22 de diciembre de 1533.

${ }_{14}^{14}$ José Luis Martínez: op cit., p. 36

${ }_{15}^{15}$ Fernando Benítez: Historia de la ciudad de México, México, Salvat, 1984, tomo 2, p. 32.

${ }^{16}$ Guillermo Tovar de Teresa: La ciudad de México y la utopia en el siglo XVI, presentación de Silvio Zavala, México, Seguros de México, 1987

${ }^{17}$ Francisco Cervantes de Salazar: México en 1554 y Túmulo Imperial, edición, prólogo y 
A su espalda se localizaba la cárcel de la ciudad además de la carnicería.

El crecimiento dentro de las funciones municipales que ejercía el Cabildo obligó al Ayuntamiento en 1562 a adquirir el predio que se encontraba anexo al edificio, entre las casas de Cabildo y la Callejuela y que ocupaba la primitiva casa de Moneda, donde era sellada y quintada la plata, ampliando así la extensión del palacio. Es posible que en 1566 el alarife Claudio de Arciniega, primer arquitecto de la Nueva España, haya participado en las obras de renovación del edificio. En 1561 se cita por primera vez a Arciniega en las actas de Cabildo, y desde febrero de 1563 se le relaciona con la construcción de la Catedral Metropolitana. Es por esos años que también participó en la edificación del Palacio Real, siendo entonces virrey don Luis de Velasco, de quien era favorito el arquitecto. ${ }^{18}$

El 31 de junio de 1572 se acordó nuevamente realizar mejoras materiales al inmueble, esta vez en ocasión del solemne recibimiento del virrey Martín Enríquez de Almanza y de la Real Audiencia con motivo de los festejos conmemorativos por el nacimiento del príncipe de España y de la victoria de Lepanto . Así se notificó a Gerónimo López, maestro mayor, y a Miguel Martínez, alarife, que se deberían apuntalar los corredores altos y bajos de la casa de Cabildo, para que estuvieran fuertes y reparados en la fecha requerida. ${ }^{19} \mathrm{El}$ inmueble seguramente no reunía en esas épocas los espacios necesarios para las actividades de la corporación, por tanto en abril de 1581 "después de haberse dado diversas providencias para que se hiciesen pilares en las casas de cabildo para hacer la fábrica de la alhóndiga", así como para la reparación del edificio se encargó al obrero mayor la terminación de las casas contiguas a la cárcel mayor. El 14 de mayo de 1582, "vista la planta de las casas de la ciudad",20 se divulgaron las condiciones necesarias para rematarse la fábrica del palacio. Para el 25 de enero de 1583 se pidió en el Cabildo que el obrero mayor Guillén Brondat comenzara la obra del corredor del edificio, además del empedrado del portal de la planta baja. Asimismo se le encargó que en el "rincón frontero" realizara la construcción de una capilla de "verjas torneadas" con altar para decir misa, ya que hasta ese momento se encontraba una improvisada en la sala

notas de Edmundo O'Gorman, 5a cdición, México, Porrúa, 1982 (“Sepan Guántos ...", 25), pp $45-46$.

${ }^{18}$ Manuel Toussaint: Claudio de Arciniega, arquitecto de la Nueva España, México, Universidad Nacional Autónoma de México, Instituto de Investigaciones Estéticas, 1981 (Monografías de Arte 5), pp. 34, 40

${ }_{19}$ Acta de Cabildo: 31 de junio de 1572.

${ }^{20}$ Pedro Gualdi: Monumentos de Méjico tomados del natural y litografiados por Pedro Gualdi en el año de 1841, edición fácsimilar, presentación de Luis Ortiz Macedo, México, Fomento Cultural Banamex, 1982 
del Cabildo. ${ }^{21}$ Los temblores constantes que se sucedían en la ciudad motivaron que en 1590 se acordara, ante la inminente visita del virrey Álvaro Manrique de Zúñiga y de la Audiencia, con motivo de las "justas de toros y cañas", que el obrero mayor Andrés Vázquez apuntalara todas las paredes del palacio, ya que sus estructuras se encontraban muy débiles. ${ }^{22}$

La última noticia de relevancia referente al palacio del Ayuntamiento durante el siglo XVI, es el acta de Cabildo del 12 de noviembre de 1590, con la orden del libramiento de cien pesos oro común a nombre de Claudio de Arciniega, por la realización de su trabajo como proyectista en las obras de la cárcel, en el interior del inmueble. ${ }^{23}$

El edificio contaba en aquel tiempo con las oficinas del Ayuntamiento que presentaban una sola entrada por el centro del portal con su zaguán, "provisto de quixaleras y tejuelos en lugar de bisagras" "La única escalera existente cerraba el frente del acceso "y después de un corto tramo daba vuelta para seguir paralela a la fachada". Todavía no contaba con patio y respecto a las tiendas de la planta baja "en la esquina de la Monterilla había un cajón de ropa y en la esquina de la Callejuela otro, ambos propiedad de los Hermanos Palacios". ${ }^{24}$ La lonja se ubicaba también en la parte baja del edificio: en esta institución se reunían los comerciantes con el fin de divertirse o de realizar transacciones comerciales. Así transcurriría la vida en este inmueble conocido también como de la Diputación durante el primer siglo de vida novohispana.

En los inicios del siglo XVII, dando paso a nuevos cánones estéticos y arquitectónicos, la primera construcción desapareció casi en su totalidad. Para 1619 se construía ya el nuevo edificio, en el mismo lugar, presentando en su decoración exterior "balcones y portales". ${ }^{25}$ Hacia 1638 el Cabildo inauguró una nueva época gubernativa, contando desde entonces con un primer corregidor nombrado por Felipe II, que vendría a sustituir a los alcaldes ordinarios que desde los inicios del gobierno municipal elegían a sus capitulares Al mismo tiempo la ciudad de México representaba el poder político, económico y religioso más importante no sólo de la Nueva España, sino también de muchas otras provincias españolas. ${ }^{26}$ Artísticamente los edificios oficiales crearon su propio prestigio frente a la arqui-

${ }^{21}$ Acta de Cabildo: 25 de enero de 1583

${ }^{22}$ Idem, 5 de febrero de 1590

${ }^{23}$ Idem, 12 de noviembre de 1590 .

${ }^{24}$ José Lorenzo Cossío: Del México viejo, prólogo de Félix F. Palavicini, sin editorial, 1934, pp. 134-135.

${ }^{25}$ Francisco de la Maza: La ciudad de México en el siglo xvII, México, Fondo de Cultura Económica, 1968 (Presencia de México, 2), p. 62.

${ }^{26}$ Manuel Alvarado Morales: "El Cabildo y regimiento de la ciudad de México en el siglo 
tectura de la ciudad, convirtiéndose en "modelos artísticos a seguir". A la par, tanto los maestros mayores como las mismas construcciones oficiales fueron "un factor decisivo en el desarrollo de la arquitectura virreinal mexicana" "27

A partir de 1682 el palacio contó con oficinas para las diversas actividades dependientes del mismo, dadas las nuevas ordenanzas del gobierno citadino. Continuaba así el diario transcurrir de la vida en la ciudad hasta que el 8 de junio de 1692, después de setenta años de erigido, el edificio fue destruido por el incendio que provocó el pueblo, en el motín surgido a causa de la agobiante escasez de maíz que padecía la ciudad. Para las seis de la tarde ardían en la plaza el Palacio Real, la Horca, los cajones comerciales y las casas de Cabildo. El ilustre don Carlos de Sigüenza y Góngora logró rescatar gran parte de los libros capitulares de la quemazón; el mismo intelectual menciona que "ya con una barreta, ya con una hacha, cortando vigas, apalancando puertas, por mi industria se le quitaron al fuego de entre las manos no sólo algunos cuartos de Palacio, sino tribunales enteros, y de la ciudad su mejor archivo"."28 Sin tan valiosa presteza se hubiera perdido la historia de nuestra ciudad. Para el Ayuntamiento el incendio significó la pérdida de su fuente de ingresos más lucrativa, puesto que desaparecieron las tablas y las tiendas de carne que representaban más de “ $\$ 150,000$ de rentas percibidas anualmente por el alquiler de ellas". ${ }^{29}$ En octubre del mismo año se presentó un proyecto y presupuesto para la reconstrucción del edificio, que sin embargo no se llevó a cabo. ${ }^{30}$

Las ruinas permanecieron por muchos años y fue hasta ya entrado el siglo XVIII que el virrey Fernando de Alencastre Noroña y Silva, en decreto del 26 de noviembre de 1714, dispuso la reconstrucción del palacio. Se ordenó el inicio de la nueva fábrica de las casas de Cabildo, la cárcel y la alhóndiga que junto con el pósito se encargaban del abastecimiento de los granos de primera necesidad; el propósito fundamental de estas dos instituciones era el mantenimiento del precio bajo de los cereales, para el

XVII - Un ejemplo de oligarquía criolla", Historia mexicana, año XXVIII, núm 4 (112) México, El Colegio de México, abril-junio de 1979, pp. 489-514

27 Martha Fernández: La arquitectura de la ciudad de México en el siglo xvII, México, Departamento del Distrito Federal, 1987 (Ciudad y Cultura, 2), p. 23.

${ }_{28}$ Carlos de Sigüenza y Góngora: Teatro de virtudes politicas - Alboroto y motin de los indios de México, prólogo de Roberto Moreno de los Arcos, México, Universidad Nacional Autónoma de México, Coordinación de Humanidades - Miguel Ángel Porrúa, 1986 (Biblioteca Mexicana de Escritores Políticos), p. 209.

${ }^{29}$ Manuel Carrera Stampa: "Planos de la ciudad de México (Desde 1521 hasta nuestros días)", Boletín de la Sociedad Mexicana de Geografía y Estadística, año LXVII, núm 2-3 (México, marzo-junio de 1949), p. 308

30 Acta de Cabildo: 1o de octubre de 1692. Agradezco el dato a la maestra Martha Fernández. 
beneficio social de la comunidad ${ }^{31}$ En esa ocasión se comisionó al marqués de Altamira la dirección de la obra. Cuatro años antes, el primero de junio de 1710 , se había contratado al alarife Rodrigo de Rivera para la construcción de la cárcel, pero nunca concluyó la obra ya que falleció en el transcurso de la misma. Pese al decreto expedido en 1714 no fue sino hasta 1720 que se inició la edificación del tercer inmueble; la obra estuvo finalmente a cargo del conde del Fresno de la Fuente, regidor de la ciudad, y de don Juan Antonio Vázquez, tesorero mayor de los propios y rentas de la misma. Los trabajos se realizaron entre el 3 de octubre de 1720 y el 4 de febrero de 1724, fungiendo como maestro alarife Antonio Álvarez, y como sobrestante Ambrosio Díaz. ${ }^{32}$ Para 1722 ya se encontraba concluido el portal, y la reedificación total se entregó en 1724 como ya se mencionó. El edificio denominado generalmente como manzana de la Diputación comprendía las calles de la Monterilla (hoy 5 de Febrero), San Bernardo (actualmente Venustiano Carranza), la Callejuela (20 de Noviembre) y la Diputación (costado sur de la plaza de la Constitución).

Debido a la falta de estabilidad económica que constantemente afectaba al Cabildo, las subsecuentes modificaciones que se realizaron en el inmueble fueron, en su mayoría, simples reacomodos de las oficinas sin intervención de obra alguna cuando el espacio desocupado era compatible con la nueva función. En caso contrario se realizaron adaptaciones a los locales del portal, reduciéndolos o ampliándolos conforme a las nuevas actividades de las dependencias. A pesar de las diversas reformas internas y externas, todas las obras estuvieron siempre acordes con la arquitectura del momento. En aquellos años el palacio se distinguió por guardar la unidad de estilo; su fachada estuvo concluida en un sobrio barroco y se encontraba entre dos torreones cuadrangulares con tres cuerpos: el primero ocupado por tiendas que incluian en su interior una pieza comunicada con la calle y algunas otras tiendas que presentaban habitaciones sobre ellas. No olvidemos que el Ayuntamiento rentaba los locales a diversos comerciantes con el fin de allegarse los fondos necesarios para cubrir sus necesidades económicas. Asimismo, la fachada presentaba un pórtico de arquería compuesto por doce arcos rebajados, que descansaban sobre sólidas pilastras. Mostraba el edificio una riqueza omamental en los marcos de los balcones que daban a la plaza dispuestos simétricamente con la arquería de los portales. Finalmente, en lo alto de la fachada se localizaba

\footnotetext{
${ }^{31}$ Manuel Carrera Stampa: op. cit., p. 296

32 Cuadernos de los gastos hechos en la obra de la cárcel puiblica de esta nobilísima ciudad, casas de Cabildo, tiendas y demás oficinas. Documento proporcionado por Guillermo Tovar de Teresa.
} 
un pretil "formado por arcos invertidos con estípites a sus extremos". ${ }^{33}$ Por su puerta principal se llegaba a un gran patio rodeado de arcos que correspondían a los corredores; al fondo se localizaba una escalera de cantera que conducía a las oficinas y despacho del corregidor. En la planta alta se encontraba la casa del gobernante y en otra sección existían las recámaras y la sala de peinado, además de la capilla familiar y las oficinas privadas.

En el interior había cuatro casas de dos pisos que eran rentadas; también se encontraban la alhóndiga y la cárcel de hombres que rodeaba a un pequeño patio. En la planta superior se localizaba la cárcel de mujeres de proporciones más pequeñas. Exteriormente, por la calle de la Callejuela, el edificio albergaba a la carnicería de la ciudad, establecida allí para que el Cabildo pudiera controlar tanto el precio como la calidad de la carne que se distribuía. Este establecimiento por su naturaleza "exigía gran concurrencia de gente, y el tráfico de las mulas que servían para la conducción de las piezas". 34

En el primer piso, la parte que daba hacia la plaza mayor se hallaba ocupada por las oficinas del gobierno citadino: el despacho del corregidor, la sala principal y su antesala, las oficinas y la sala de Cabildos, que era el recinto más grande del inmueble y que se ubicaba en la esquina poniente del palacio, además de la contaduría y la tesorería.

De la arquitectura de este edificio dieciochesco se puede remarcar la poca variación en su estructura con respecto al común de la arquitectura civil de la época, confirmando que "lo que llamamos proceso del estilo barroco alte[ró] sólo la piel de esas estructuras arquitectónicas que resul$\mathrm{ta}[\mathrm{ron}]$ ser siempre las mismas". 35

En el transcurso del siglo XVIII la burguesía fue tomando una sólida fuerza que la llevaría a ser el grupo rector de las decisiones en el destino histórico de Occidente; "nueva poseedora de la autoridad, la burguesía, para hacer sensible y entretejer la idea de su poder en la mente de las gentes, se sirvió precisamente de los símbolos y las formas que, en el arte y la arquitectura, crearan las jerarquías que había venido a sustituir" "\$6 La

\footnotetext{
${ }^{33}$ Salvador Novo: La vida en la ciudad de México en 1824, colaboración de Miguel Capistrán, nota introductoria de René Avilés Fabila y presentación de Miguel León-Portilla, México, Departamęto del Distrito Federal, 1987 (Colección Distrito Federal, 12), p. 405.

${ }_{34}$ Idem, p. 106

35 Jorge Alberto Manrique: "La formación de la arquitectura barroca americana", Nuestra América, año I, núm. 3 (México, Centro Coor dinador y Difusor de Estudios Latinoamericanos, septiembre-diciembre de 1980, p. 86.

${ }^{36}$ Fausto Ramírez: "Reflexiones sobre la aparición de nuevos programas en la arquitectura decimonónica en México", Anales del Instituto de Investigaciones Estéticas, XII, núm. 48 (México, Universidad Nacional Autónoma de México, 1978), p. 89.
} 
Real Academia de las Tres Nobles Artes de San Carlos de la Nueva España, promovida por el grabador Gerónimo Antonio Gil y que abrió sus puertas en los años 1782-1783, fue la directora didáctica del gusto general hacia el neoclasicismo y precisamente éste sería la negación del arte barroco. Así, con la Academia, México entró a la modernidad artística de fines del siglo XVIII. ${ }^{37}$

Entre los arquitectos notables del momento se destacó Ignacio de Castera, quien participó en destacadas obras públicas (su notable proyecto urbanístico para la ciudad) y en significativas obras religiosas (la iglesia de Loreto). Hacia 1783 Castera presentó al virrey Matías de Gálvez y Gallardo, a la vez que al regidor Francisco Antonio Crespo, una relación de obras que necesitaba el palacio del Ayuntamiento, entre las que se contaban la construcción de cuatro accesorias de "taza y plato", como prolongación de la serie de tiendas que se encontraban sobre la calle de San Bernardo, con el fin de incrementar los ingresos por rentas para el municipio. En el espacio que quedaba libre sugirió que se reconstruyera la cárcel de mujeres, que contaría con dos calabozos, uno arriba del otro, además del patio de reclusas que hasta entonces no existía.

A solicitud del Cabildo, el maestro Castera presentó una relación de obras que requería la oficina de la alhóndiga:

El maestro mayor y veedor de Arquitectura, de esta Novilisima Ciudad.... he calculado lo que se podría erogar, en el preciso reparo que necesita, la oficina de la alhóndiga principal, y respecto a hallarse tan maltratada, necesita techar de nuebo los Cañones orizontales, en lugar de los Brocales de mampostería que tiene, unos varandales de fierro, a fin de evitar el mayor peso que causan los primeros, ampliando así mismo los primeros, ampliando así mismo los Tejados, que las resguardan de la agua temporal .... considerados los materiales que se pueden aprovechar, asciende a la cantidad de un mil pessos, poco mas o menos... ${ }^{38}$

Seguramente estos trabajos no se realizaron puesto que el 26 de mayo de 1784 los maestros mayores josé joaquín García de Torres y José de Álvarez, además del mismo Castera, informaron al Cabildo sobre el estado y las obras que se requerían en la oficina de la alhóndiga:

Se hallan maltratados mucha parte de las Tablas podridas, los Ladrillos de las

${ }^{37}$ Jorge Alberto Manrique: El Museo Nacional de Arte, México, Instituto Nacional de Bellas Artes, Secretaría de Educación Pública, 1989, p. 17.

${ }_{38}$ Archivo Histórico de la Ciudad de México: Manzana de la Diputación, vol. 1087, exp. 17. (En lo sucesivo A.H.C.M.) 
Azoteas y mui enlamados, y por consiguiente sin disposición para recibir los rebocados, concideramos ser necesario poner dichos Techos y renuebo .... y en quanto a la alhóndiga necesita de nuebo los Techos laterales contiguos a las Paredes, por hallarse podridas las maderas las que por hallarse apuntaladas escusan una próxima Ruina ${ }^{39}$

Por lo visto tampoco fueron realizadas estas reparaciones puesto que el 26 de agosto de 1785 el Cabildo acordó de nueva cuenta se hiciera una revisión del estado del edificio, principalmente la casa del corregidor, ordenando se procediera a su reparación el 21 de marzo de 1786.

El 2 de julio de 1787, siendo entonces virrey y arzobispo de México Alonso Núñez de Haro y Peralta, Castera presentó nuevos planos que modificaban al palacio con propuestas más radicales. Basado en las Ordenanzas de Intendentes de 1786, propuso una nueva "colocación de las correspondientes oficinas de la Intendencia, completan[do] la Casa del Señor Intendente, dejando en mejor situación la Lóndiga, Carnicerias, y Carzel, con aumento de la capacidad que en el día tiene quedando igualmente todas las tiendas y demas Casas de Comercio, y particulares" " ${ }^{40} \mathrm{El}$ arquitecto proyectó sin tocar ningún comercio ni casas particulares de las que se "encontraban en las calles que comprendían el cuadrante del edificio", salvo la casa de la calle de Cordobanes que se tenía que reconstruir, puesto que se encontraba muy maltratada. Castera estableció así las pautas para la nueva distribución de la casa del Cabildo.

En el proyecto presentado por Castera se advierte su preocupación por no alterar el aspecto arquitectónico del palacio, sobre todo cuando señala, refiriéndose a los lugares por reedificar, que "cualquiera otro Sitio que para esto se elija, desproporciona la Fachada principal ó Simetria del Edificio". ${ }^{41}$ Al mismo tiempo se debe recalcar el interés constante que manifestó por mejorar el funcionamiento de la corporación que reunía a varias dependencias con diversas actividades administrativas. En ese momento y en muchos otros a lo largo de sus trabajos en el Palacio del Ayuntamiento, Castera se comportó como el "primer arquitecto restaurador" de la Nueva España, puesto que exigió que no se modificaran y se conservaran los elementos decorativos y la fachada del inmueble, "por guardar una armonía y unidad formal". 42

${ }^{39}$ Idem.

${ }^{40} \mathrm{Idem}$

${ }^{41}$ A.H.C.M : Manzana de la Diputación, vol. 1087

42 Alberto Yáñez Salazar: "El Edificio de Cabildo de la Ciudad de México", en Ramón Gutiérrez et al:: Cabildos y Ayuntamientos en América, México, Instituto Argentino de Investiga- 
En 1790 durante el gobierno político del virrey Juan Vicente de Güemes Pacheco, segundo conde de Revillagigedo, y quien "fué de los pocos gobernantes, y el que más se preocupó por limpiar, engrandecer y embellecer a la ciudad de México", Castera, su arquitecto "consentido",43 trabajó nuevamente otro proyecto, muy similar al de 1787 , en el que se advierte una sola corrección substancial y pequeñas reformas para mejorar el funcionamiento de algunas de las dependencias del edificio. Según este proyecto, la disposición sería la misma de tres años antes, salvo nuevas reparaciones aisladas. En esta ocasión, a causa de razones de estado que distraían la atención del Ayuntamiento, las obras tampoco fueron realizadas.

Hasta aquí las noticias concernientes a la destacada participación, en las obras del Cabildo, del maestro mayor que "representó a la modernidad novohispana como pocos y con Academia de San Carlos o sin ella hubiera destacado por su talento". Gracias a la incomprensión que la insigne institución le manifestó, Castera fue incorporado a los trabajos oficiales que el virrey Revillagigedo requería en la ciudad. ${ }^{44}$

Los intentos por corregir las deficiencias que prevalecían en la distribución de las oficinas del palacio motivó que en 1791 el ingeniero Manuel Agustín Mascaró presentara otro proyecto más, que modificaba ligeramente el de 1790; propuso que se situaran frente al portal de la calle de la Diputación cubículos para oficios particulares y de escribanos, así como para la policía y los correspondientes al cuerpo de guardia para tropa y sargento. En estos nuevos planos el acceso al patio de la casa del corregidor se hacía por una sola entrada; inmediatamente se localizaba la escalera principal que conducía a los aposentos del regidor; a los lados del claro proponía el cuarto para leña y carbón, una bodega y, más al fondo, un depósito de basura y estiércol; en el lugar que anteriormente ocupaba la escalera de intendencia se proyectaba una cochera.

A la alhóndiga también se le hacían algunas reformas: se acortaba una de las trojes para convertir el espacio en almacén general para los enseres del Cabildo. Se ubicaba una escalera junto a la entrada además de un ducto para la ventilación de los calabozos que colindaban con el almacén. Pese a todo, el proyecto no difería mucho del anterior.

El 20 de mayo de 1797 el arzobispo Núñez de Haro y Peralta giró una

ciones en Historia de la Arquitectura y el Urbanismo - Universidad Autónoma Metropolitana Azcapotzalco-Tilde, 1990, p. 101

43 Francisco de la Maza: "El urbanismo neoclásico de Ignacio de Castera", Anales del Instituto de Investigaciones Estéticas, VI, núm. 22 (México, 1954), p. 93.

${ }^{44}$ Guillermo Tovar de Teresa: "Arquitectura efímera y fiestas reales: la jura de Carlos IV en la ciudad de México", Artes de México, nueva época, núm. 1 (México, otoño de 1988), p. 52. 
licencia, certificada cinco años después, en la que autorizaba oficiar misa en la capilla de la sala capitular. ${ }^{45}$ Se concedió que

con cualquier Sacerdote Secular, o Regular, aprovado en nuestro Arzobispado, pueda celebrarse sin perjuicio del derecho parroquial, el Santo Sacrificio dela misa, todos los días del año aun los prohividos por año, excepto el Jueves, Viernes y Sabado de la Semana Santa. Para ese entonces la capilla estaría "decente, y abundantemente prevista de Basos sagrados, y demas Utensilios correspondientes al Culto del Señor". ${ }^{46}$

Para finalizar el siglo, en 1795 se realizó un cambio más en el palacio: el Cabildo ordenó que se redujera la vivienda del corregidor, aprovechando los locales y las piezas que se encontraban desocupados, para ampliar la cárcel de hombres, la de mujeres y la alhóndiga según los planos realizados por Castera y Mascaró.

Entre 1808 y 1867 el Estado mexicano vivió quizás una de las peores crisis de su historia; la sociedad novohispana sufrió la inestabilidad política, la guerra y la aparición de fracciones partidistas que pretendían implantar nuevos rumbos a la nación. El vasto "esfuerzo que en la segunda mitad del siglo XVIII realizan los borbones para obtener mayores ingresos de la colonia y mantenerla más sujeta, comienza a derrumbarse con el golpe de estado que en 1808 dirige la oligarquía peninsular y depone al virrey Iturrigaray". ${ }^{47}$

A lo largo de ese tiempo, el Ayuntamiento continuó con sus permanentes remodelaciones, el 7 de noviembre de 1804 el arquitecto mayor Joaquín de Heredia realizó un reconocimiento de las escaleras que daban a las viviendas, hallando que estaban "solo de dos tramos, en una altura más que

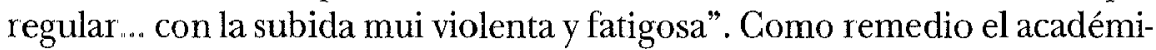
co de mérito de la Real Academia propuso "repartir su altura en tres, ó quatro, tramos de Escalera, de lo que resultara mucho más comoda, sin comparación, que la presente, y de mayor firmeza... con todas las proporciones y reglas que prescribe el Arte". ${ }^{48}$

A tal grado el gobierno de la ciudad se había visto en la necesidad de alquilar prácticamente toda la parte baja de su sede, para allegarse más

${ }^{45}$ Jorge Nacif Mina: "Licencia del Arzobispo para celebrar misa en la capilla de la Sala Capitular, en el año de 1791, certificada en 1796", en Boletin del Centro Histórico de la Ciudad de México, año 2, núm 15 (México, Departamento del Distrito Federal, marzo de 1985), pp. 4-6

${ }^{46}$ A.H.C.M.: Manzana de la Diputación, vol. 1087, exp. 3.

${ }^{47}$ Enrique Florescano: El poder y la lucha por el poder en la historiografia mexicana, México, D. I H.-Instituto Nacional de Antropología e Historia, 1980 (Cuadernos de Trabajo, 33), p. 31.

${ }^{48}$ A. H.C.M.: Manzana de la Diputación, vol. 1087, exp. 3 
recursos económicos -nunca suficientes-que en el año 1836 se suscitó un problema entre la corporación y los locatarios que rentaban los locales bajos, a causa de que el cuerpo municipal pretendía que le fueran cedidos varios locales para las oficinas de sus autoridades. En esa ocasión se elaboró un dictamen, fechado el 16 de enero de 1836, en el que se explicaba a la autoridad municipal la situación; el uso inconveniente del inmueble fue la causa de los mencionados problemas ${ }^{49}$ Su destino, que era el de residencia del Ayuntamiento y la atención al público fue en parte olvidado: los corregidores, como miembros del gobierno de la ciudad, tuvieron vivienda en el palacio, "mas extinguido ese empleo, el último individuo que lo sirvió permaneció hasta su muerte en la habitación sin título alguno, á pesar de frecuentes reclamos" ${ }^{50}$ Posteriormente, algunos gobernadores del distrito, ya en tiempos de la Federación, también harían lo mismo, perjudicando a los fondos del Municipio.

La cárcel de la ciudad ocupó espacio en el edificio hasta que una orden suprema del 26 de octubre de 1835 la extinguió "quedando solo un corto depósito de detenidos", ocupando dos piezas del mismo. El local de la alhóndiga se encontraba ya en ese entonces ocupado por comercios.

El furor de la guerra independentista repercutió también en el Ayuntamiento dañando seriamente tanto partes externas como internas del inmueble. Su aspecto hacia 1840, posteriormente a los sucesos, nos los muestra en magnífica litografía Pedro Gualdi, quien describe la fachada así:

no pertenece á ningun órden de los cinco de arquitectura; los machones é impostas de los arcos se acercan al órden dórico, pero las arqui-voltas y cornizas son caprichosas y del gusto churrigueresco. El piso alto es sumamente sencillo, y lo corona una corniza de pocas molduras, y las canales sostenidas con ménsolas mui adornadas de arabescos. En los ángulos de esta fachada hai dos cuartos, que sirven como de torrecillas, y estas, lo mismo que toda la fachada, tienen unas almenas cuadrangulares y piramidales, y en el centro el escudo de armas de la nación. ${ }^{51}$

Los días 7 y 10 de abril de 1845 se sintieron dos sismos en la ciudad de México que causaron considerables daños a diversos edificios; de los pertenecientes al gobierno, el de la Diputación sufrió los mayores estragos. Don Rafael de la Peña, regidor de los cuarteles 7, 8, 9 y 10 en la ciudad, hizo un reconocimiento al edificio y señaló que "lo más amenazante fueron

\footnotetext{
${ }^{49}$ A.H. C.M. : Manzana de la Diputación, vol. 1088, exp 37

${ }^{50}$ Pedro Gualdi: op cit

${ }^{51}$ Idem
} 
dos techos vencidos al oriente, uno en los lavaderos de la vivienda del licenciado Alcocer y otro en el cuarto en que antiguamente se guardaban las candilejas de las iluminaciones. Ambos ocasionaron el desplome de una pared. Se mandaron demoler". 52

Posteriormente, el Diario del Imperio de marzo de 1865 nos da una idea de las condiciones caóticas en las que se laboraba en las oficinas del Ayuntamiento. El secretario general del mismo, licenciado Juan A. Mateos, escribió sobre la necesidad imperante de disponer por completo del inmueble, sugiriendo que se realizaran "mejoras sin destruir", siendo prudentes y justas. Contempló el ordenamiento de las oficinas políticas "dividiéndolas y acomodándolas con tabiques de poco costo", debido a que el Ayuntamiento presentaba en sus oficinas superiores un "local tan estrecho y mal repartido, cortado por sucios callejones ó pasadizos", que no podía haber "el silencio y mesura que dan respeto a la autoridad". 53

En este artículo también se habla de la situación que prevalecía en el Archivo Municipal que contenía, según "cálculo prudente", más de cuatrocientos mil documentos "ó piezas chicas y grandes de todas épocas". Para mejorar el salón que lo contenía, después de "poner alambrados y llaves á todos los estantes con tres bastidores y vidrieras" para proteger los libros, se sugería dividir el acervo en cuatro secciones diferentes: la primera con ramos "estraños, protocolos, etc., que se depositan allí por ley, aunque están á cargo de un escribano que no es el archivero"; la segunda conteniendo todos los documentos del siglo XIX y que irá organizando el archivero incesantemente; la tercera recopilando el archivo de Beneficencia, además de la sección Junta o mesa del ramo, y por último la cuarta con todos los documentos anteriores a 1800 "que no son de necesidad tan inmediata y que podrán inventariarse después". Con estas reformas las más importantes para el archivo desde que se había iniciado en 1524 con el primer documento del Cabildo dividiéndolo y asegurando los acervos en los estantes, se podría dar "orden para lo corriente y para lo atrasado, hasta el año de $1860 " .{ }^{54}$

Diciembre de 1886 es la fecha correspondiente a otro proyecto de reformas y mejoras en el palacio, en esta ocasión realizado por los ingenieros Antonio Torres Torija, Mateo Plowes y Emilio Dondé. ${ }^{55}$ Por su parte, a

\footnotetext{
52 María Concepción Amerlinck: Relación histórica de movimientos sismicos en la ciudad de México (1300-1900), prólogo de Luis Ortiz Macedo, México, Sociocultur, 1986, p 72.

${ }^{53}$ Juan A. Mateos: "Ayuntamiento de México", en Diario del Imperio, I, núm. 54 (México, martes 7 de marzo de 1865), pp. 219-220.

${ }^{54}$ Idem, pp. $219-220$

${ }^{55}$ A.H.C.M.: Manzana de la Diputación, vol 1088, exp. 71
} 
fines de 1890 el arquitecto Antonio Rivas Mercado también realizó su proyecto, presentado a la Comisión de Obras Públicas, proponiendo reformar la fachada basado en sus estudios realizados durante su estancia en tierras europeas ${ }^{56}$

Participación relevante dentro de las obras llevadas a cabo en aquellos años, son los trabajos en 1892 del magnífico escultor mexicano Gabriel Guerra, quien realizó las obras de bronce para el ornato del plafón de la sala de Cabildo. Conjuntamente trabajó el pintor Félix Parra ejecutando la pintura que decora el plafón de la misma y que representa una alegoría en el cielo raso, en la que figuran, entre diversas personalidades, los escritores Luis G. Urbina y Amado Nervo. Estas obras afortunadamente subsisten y en ellas demostró Guerra "pleno dominio de la composición decorativa" . ${ }^{77}$ Los trabajos ornamentales se deberían terminar antes del 15 de marzo de 1893, salvo caso fortuito o de fuerza mayor debidamente comprobado. El Cabildo pagó a Guerra la cantidad de 2200 pesos remunerados en partidas de 500 pesos mensuales a partir de diciembre de 1892. Previo a este contrato el escultor había entregado un presupuesto el 8 de octubre del mismo año, donde pedía por la realización de la obra 2368 pesos. A fines de 1893 el artista se encontraba muy enfermo y no pudo presentarse en las oficinas del Ayuntamiento para recibir el saldo que se le debía por la terminación de su trabajo, por lo que solicitó que aquel adeudo se le entregara a Parra ${ }^{58}$ Gabriel Guerra ya no se recuperó de sus males y murió el 8 de noviembre del mismo 1893 a la edad de 46 años. ${ }^{59}$

Para el 12 de mayo de 1898 la Comisión de Hacienda, por conducto del licenciado Miguel S. Macedo, emitió una propuesta referente a la distribución del palacio municipal, con el fin de concentrar todas las oficinas del Ayuntamiento en un mismo lugar, liberando al edificio de los comercios que todavía se encontraban en su planta baja. Sin embargo, dos incisos de la referida propuesta no fueron respetados ni siquiera el mismo año de su redacción: la tercera cláusula que prohibía variar la distribución del inmueble, es decir que no se podía ejecutar obra alguna si no correspondía con el proyecto presentado; y la cuarta cláusula en la que se ordenaba no celebrar en lo sucesivo ningún contrato de arrendamiento de locales en el palacio, ni que se prorrogara contrato alguno de los que estaban en vigor

\footnotetext{
${ }_{57}^{5}$ A.H.G.M.: Manzana de la Diputación, vol. 1090, $\exp 130$

${ }^{57}$ Marco Díaz: Gabriel Guerra (1847-1893) una voluntad escultórica, México, Museo Nacional de Arte, 1986, p. 7 .

${ }_{58}$ A.H.C.M: Manzana de la Diputación, vol 1088, exp. 71

${ }^{59}$ Manuel G. Revilla: "Biografía de Gabriel Guerra", en Gabriel Guerra (1847-1893); una voluntad escultórica, México, Museo Nacional de Arte, 1986, p. 29
} 
hasta el 15 de abril de 1900 "para los locales que quedan al Poniente de la entrada principal", ni de los vigentes hasta el 31 de agosto de 1902 "para los que quedan al Oriente de la misma entrada". ${ }^{60}$

Efectivamente, no se renovó ningún contrato para los locales de la entrada principal, pero en lo que respecta a la parte posterior, el gobierno desoyó las recomendaciones hechas y decidió otorgar, con fecha 29 de octubre de 1898, un contrato de compra-venta de una fracción del patio del edificio a favor del almacén El Palacio de Hierro.

Por ley del 26 de marzo de 1903, habiéndose cambiado la organización del gobierno citadino por órdenes de Porfirio Díaz, el palacio pasó a formar parte de la Federación, responsabilizándose de su mantenimiento la nueva Dirección de Obras Públicas. El Ayuntamiento continuó laborando en el edificio pero el Consejo de Gobierno, de común acuerdo con el Ejecutivo, decidió realizar las reformas necesarias para hacer del recinto una "recidencia digna de las autoridades que tienen directamente á su cargo la administración política y municipal del distrito federal". ${ }^{61}$ Los trabajos se encomendaron al arquitecto Manuel Gorozpe de acuerdo con el proyecto que presentó previamente al director de Obras Públicas. Asimismo se vendió otra fracción más al mismo almacén comercial en 88000 pesos. El presupuesto total de la obra era de 400000 pesos y los trabajos se terminarían en 1910 , para la gran fiesta conmemorativa del centenario de la Independencia ${ }^{62}$ La obra de albañilería y cantería de la fachada principal, así como de los torreones, se concertó el 25 de octubre de 1909 entre el ingeniero Guillermo Beltrán Puga, director de Obras Públicas, y el señor Caesar J Marburg, de la Compañía Italiana de Construcciones, $\mathrm{SA}^{63}$ En el siguiente mes ya se encontraba concluido el lienzo de fachada de la calle de la Monterilla, segándose los arcos construidos en el siglo XVIII, y quedando en su lugar balcones ${ }^{64}$

La mejoras no fueron terminadas en el plazo establecido ya que en diciembre de 1909 el Boletín Oficial comentaba el hallazgo, durante la

${ }^{60}$ A.H. C.M : Manzana de la Dipulación, vol 1090 , exp 149

${ }^{61}$ Jesús Galindo y Villa: "Las reformas del Palacio Municipal quedarán terminadas para el Centenario de la Independencia", en Boletin Oficial, VIII (México, Gobierno del Distrito Federal, 23 de abril de 1907), p. 501.

62 Jesús Galindo y Villa: "La fachada del Palacio Municipal", en Boletin Oficial, VIII, núm. 32 (México, Gobierno del Distrito Federal, 23 de abril de 1907), p. 503

${ }_{63}$ Boletín Oficial del Depar tamento del Distrito Federal: Dirección General de Obras Públicas - Contrato, XIII, núm 39 (México, Gobierno del Distrito Federal 12 de noviembre de 1909), p. 631.

${ }^{64}$ Idem. Adiciones al Presupuesto de Egresos vigente, y nuevas autorizaciones para gastos de obras importantes en el Distrito Federal, XIII, núm. 44 (México, Gobierno del Distrito Federal 30 de noviembre de 1909), p. 692 
reconstrucción de la fachada, de las columnas construidas entre 1722-1724, que se encontraban envueltas por los sillares de los pilares. El mismo artículo señalaba que a la misma fachada se le seguía "con todo esmero" un acabado en "estilo colonial" para conservar la unidad con respecto al perímetro de la plaza ${ }^{65}$ En 1910, como constancia de esta nueva reconstrucción, se colocó en una de las pilastras del portal una placa de bronce en la que se lee: "Manuel Gorozpe reconstruyó el Palacio Municipal inaugurándose la fachada el 16 de septiembre de 1910".

Un año después el gobierno del Distrito Federal ya se había cambiado de local; sólo se hallaban instaladas en el edificio las oficinas del Ayuntamiento y algunas de la Dirección General de Obras. El arquitecto Gorozpe continuaba afanosamente sus obras, construyendo en ese momento el patio principal ${ }^{66}$ Los trabajos se fueron retrasando e interrumpiendo en varias ocasiones; para 1926 se terminaron los salones de la planta baja y los dos pisos altos que correspondían al patio situado al oriente. Por acabarse se encontraban los corredores del patio situado al occidente y dos salones del segundo piso y se esperaba finalizar en su totalidad la obra en fechas cercanas, gracias a la reorganización de las finanzas del Ayuntamiento ${ }^{67} \mathrm{En}$ la memoria del gobierno de la ciudad correspondiente al año $1927 \mathrm{se}$ habla de la terminación de varios salones que entraron inmediatamente en servicio, así como la continuación de las obras de cantería en los patios y corredores. ${ }^{68}$

En 1928 se tomó la decisión de destituir al sistema municipal en la ciudad de México para dar paso a la creación jurídica del Departamento del Distrito Federal; el actual edificio fue concluido en sus tres niveles en ese mismo año. El archivo del Ayuntamiento permaneció situado al extremo sur del edificio, entre la escalera interior y los muros de El Palacio de Hierro. El inmueble, a partir del primero de enero de 1929 y hasta fines de 1948, fue sede del Departamento Central; en febrero de 1930, siendo regente José Manuel Puig Casauranc, fueron proyectadas y construidas la crujía central y la escalera monumental. Por último, en 1934 se le agregó el cuarto piso, durante la regencia de Aarón Sáenz.

En el siglo XX, así como en los anteriores y desde su primera construcción, el palacio del Ayuntamiento fue modificando sucesivamente su fiso-

${ }^{65}$ Idem. Algo curioso en la fachada del Palacio Municipal, XIII núm. 44 (México, Gobierno del Distrito Federal, 30 de noviembre de 1909), p. 742.

${ }^{66}$ Idem Las obras del Palacio Municipal, XIII, núm. 39 (México, 12 de noviembre de 1909), p. 567 p. 74 .

${ }^{67}$ Ayuntamiento Constitucional de México: Memoria - 1926, Departamento de Publicidad,

${ }^{68}$ Idem. Memoria - 1927, p 138 
nomía, no tanto por ideales estéticos sino por las diversas "necesidades prácticas, intereses creados, descuido, indolencia y mil razones vanas más" ${ }^{69}$ Este importante edificio, pese a todo, ha sobrevivido a los embates reformistas de todas las épocas; es deber no sólo del gobierno capitalino, sino de todos nosotros el preservarlo incólume de cualquier intento destructivo, ya que representa una prueba objetiva de la azarosa historia de nuestra ciudad.

\section{DOCUMENTO I}

Los Maestros de Arquitectura Don Joaquin Garcia de Torres, Don Joseph de Alvarez, y Don Ignacio de Castera, en cumplimiento delo mandado por el Señor Don Francisco Antonio Crespo, Coronel de los Reales Exercitos de Su Majestad, Corregidor de esta Novilisima Ciudad é Inspector general de las Tropas de estos Reynos, passamos á reconocer la Cassa de su habitacion y la Oficina de la Alhondiga ò Depocito de Maizes que està en lo inferior de ella, como assi mismo las Troges que le son contiguas por la parte de Sur à fin de evitar los continuos gastos que se estàn originando ala Novilisima Ciudad con la repetida compocicion de Goteras, y tambien una Ruina, como que se experimentò en la cubierta dela Alhondiga, de haberse hundido veinte y tantas vigas que se hallaban podridas, en cuya inteligencia, y con el conocimiento del estado delas Maderas de todos los Pavimentos superiores de dicha vibienda que se hallan maltratados mucha parte de las Tablas podridas, los Ladrillos de las Azoteas mui enlamados, y por consiguiente sin dispocicion para recibir los rebocados, concideramos ser necesario poner dichos Techos de nuebo, y por quanto el uso dela vibienda de uno de los Mazeros, dà un preciso traqueo à estas Azoteas, serà mui combeniente, que ésta se construya contigua ala de el otro Mazero, por estàr inmediata ala Escalera, poniendo un pedazo de Pared que embarase el uso delas Azoteas para su mayor conserbacion; y en quanto ala Alhondiga nececita de nuebo los Techos laterales contiguos a las Paredes, por hallarse podridas las maderas, las que por hallarse apuntaladas escusaràn una proxima Ruina, cuya Obra se escluye de este Calculo, por estar precentando por Expediente separado, en donde consta tambien su estado, y costos por el maestro de Ciudad, las demas Trojes superiores, è interiores, se hallan en buena dispocicion, como assi mismo, los Entresuelos que caen a la Callejuela, para cuya Obra, concideramos ser preciso erogar la cantidad de un mil y quinientos pessos, no resultando otras precisas obras que à la precente no se pueden prebenir. Mexico y Mayo 26 de 1784.

${ }^{69}$ Martha Fernández: La ciudad de México de gran Tenochtitlan a mancha urbana, prólogo de René Avilés Fabila, México, Departamento del Distrito Federal, 1987 (Colección Distrito Federal, 14), p. 63. 
Joseph Joaquin Garcia de Torres.

[Rúbrica]

Joseph de Alvarez.

[Rúbrica]

\author{
Ignacio de Castera. \\ [Rúbrica]
}

A.H.C.M.: Manzana de la Diputación, vol. 1087, exp. 17, p. 6

\title{
DOGUMENTO II
}

En la Junta que celebrò esta Novilísima Ciudad de México con el Señor Oidor Juez Superintendente Conservador de Propios y Rentas. hoy diez y siete de noviembre de mil setecientos noventa y cinco, consta lo siguiente: "Dióse cuenta con el expediente formado sobre la compostura de la Alhóndiga mayor y ampliación de la vivienda del Señor Corregidor que después se extendió a la fábrica de oficinas que sirvieron a la intendencia, y teniéndose presentes los planos formados por el Maestro Mayor Don Ignacio de Castera, y el Ingeniero Manuel Agustín Mascaró. se acordó que el señor obrero mayor asociado de los Maestros Mayores pase y haga reconocimiento del estado que tienen dichas oficinas para que en consecuencia se reduzca la vivienda del Señor Corregidor por no haber ya intendencia y se trate de aprovechar las piezas que quedaren en la ampliación de la cárcel de hombres y mujeres extensión de la alhóndiga y demás que lo necesiten informando los Maestros del costo que esto tenga según los nuevos planos que levantaren y el señor Obrero Mayor lo que le ocurra para que en su vista se puedan tomar las providencias convenientes como parece del libro de Juntas a que me remito.

José Galapiz Matos.

[Rúbrica]

Arquitectura y sociedad, año XXXVIII, núm. 34, México, p. 31.

\section{DOCUMENTO III}

1 El Maestro Mayor de Arquitectura de esta Novlisisima Ciudad (....) Desague, y Agrimensor de tierras Aguas y Minas por Su Majestad (Que Dios Guarde) Presenta à Vuestra Excelencia los planos formados para la colocación de las 
correspondientes oficinas de la Intendencia, completan la Casa del Señor Intendente, dejando en mejor situacion la Londiga, Carnicerias, y Carzel, con aumento de la capacidad que en el dia tiene quedando igualmente todas las tiendas, y demas Casas de Comercio, y particulares, que haya en las calles que comprende su cuadro de la Monterilla, San Bernardo, Callejuela, y Diputación, á excepcion de la Casa de Cordovanes que justamente por antigua, y mal tratada, se devia construir, y por que esto es lo unico en que este proyecto o distribucion disminuye las rentas de esta Novilisima Ciudad por los productos de la expresada Casa de Cordovanes, propongo en donde á poca costa se pueden colocar logrando mejor Sitio; De modo, que con la mutacion que hago de las oficinas que refiero, proporciono, y parece resulta en todo mayor comodidad publica.

2 El Plan No, 1 demuestra lo baxo, y el No 2 lo alto, omitiendo el de los Entresuelos que hay solo en la Sera dela Monterilla hasta sus extremos, y en parte de la callejuela por no ser conducentes à la resolucion de esta Obra.

3 Lo encarnado demuestra toda la Fabrica existente, y lo amarillo la que se ha de hazer de nuevo, en donde por sus letreros respectivos consta el nombre de cada Pieza y oficinas, y los numeros 1,2,3,4,5, los claros delos principales Patios que comprende lo esencial de esta Distribucion.

4 En el numero 1 está en el dia la Alondiga siendo sus Puertas principales y troxes assí en lo bajo como en lo alto, las Piezas que ya con otra distribucion se demuestran con este numero. En ella ha de quedar el Patio principal de la Casa del Señor Intendente con sus respectivos Zaguanes y Escaleras como se demuestra, assí mismo dos oficios que se quitan para colocar el Quarto del Portero y Escalera, la Cavalleriza, Pajar, Cevadero, Guarnés, Quarto del cochero, id. de Lacayos, Bodega, Cocheras y Guerpo de Guardia, con las tiendas á la Callejuela como queda dicho.

5 En el numero 2 existen las Carnicerias y se coloca en su Situacion la Londiga con dos Puertas, Sitio para el Despacho, tribunal dos troxes para Maiz à granel y dos para el de apilo; de modo: Que queda, haziendose la Obra que manifiesta, en la misma conformidad y extencion que la que tiene en el numero 1 , con la ventaja de pasar sus ventilaciones à la calle de San Bernardo, aumentar sus troxes como se demuestran con el numero 2 en el Plan de lo alto; quedando libres las Oficinas de Intendencia, oficios públicos, y todo el Portál, y Calle delas Casas Capitulares desembarazado de la gente que ocurre à la compra de Maiz, la que estará con desahogo en la callejuela.

6 En el numero 3 existe el Estanco de los Cordovanes y pueden colocarse las Carnicerias haziendose la Obra que el Plan manifiesta, quedando un Patio, y Portal para este Despacho, con el lugar para colocar las tablas, dos Puertas para la libertad dela Gente, con lo que, no solo quedan como las que hay en el numero 2 sino con el aumento de dos Bodegas como se manifiesta.

7 En el numero 4 la Carzel, à la que se aumenta la de Mugeres y se coloca la Vivienda del Alcayde. 
8 En el numero 5 está el Patio que antiguamente ha sido la Casa del Señor Corregidor con dos Cocheras y Cavalleriza, que à mas de ser chica, no tenia Pajar, Cevadero ni Guarnés; en él se han puesto tres Cocheras para interín se verifica la Obra general quedando despues estas, y la Cavalleriza en bella Situacion para el aumento de Carzel; el Patio para que con una Escalera sea corral de la Casa principal, y el Zaguan en un oficio publico de que hay tanta necesidad.

9 Las Viviendas de los dos Mazeros se hallan colocadas en las torrecillas del $4^{\circ}$ piso, que por traqueo que resultaba à las Azoteas se mandó desocupar la que cae à la Callejuela pagandose por la Novilisima Ciudad la Casa en que habita el uno, interin se proporcionaba su construccion en donde no resultase los incombenientes expresados: la primera que cae à la monterilla puede subsistir en los terminos que siempre ha estado, y sobre el Cañón en donde estan los boquetes de la Carzel puede quedar la otra, porque cualquiera otro Sitio que para esto se elija, desproporciona la Fachada principal ò Simetría del Edificio.

10 Para que las Rentas que produce el Estanco de Cordovanes no se pierdan puede colocarse este con toda comodidad en los varios Jacales que hay vacios en lo interior del Parian reuniendolos a una fila, que solo costarà forrarlos de tablas, hecharles Puertas, y mostradores de que resulta beneficio, pues los que se surten de este material encuentran alli mismo los demas efectos, que para su. consumo necesitan como listones, (...)

11 La construccion de esta Obra tampoco exige prompta exibicion de Caudales à causa de no perjudicarse ninguna delas oficinas expresadas, hasta estar construida en la otra situacion su correspondiente, y aunque para la promta construccion delas oficinas de la Intendencia, se quita un tramo de las troxes altas, es por no haver otro arbitrio, ni tanta necesidad de él, las que tendran el uso por la Casa y Escalera principal del Señor Intendente interin pueden usarse por la que le corresponde. De modo, que primero se deve hazer lugar à los Cordovanes en el Parian, como queda dicho, y vacia la casa en que están construir alli las Carnicerias, expedito el lugar donde estan estas, ponen en ellas la Alondiga, y abilitada esta, concluir el Patio, y Casa del Señor Intendente, con cuya Sucesion podrá irse verificando la obra sin angustia del dinero, y necesidad de las oficinas, pues para la conclucion de las primeras, solo se necesitan Seis mil pesos.

12 Toda la Obra y mutacion de oficinas que se expresa, haziendose segun y como queda dicho ascenderá su costo à treinta mil pesos, segun mi inteligencia assi lo declaro y juro en devida forma. Mexico 2 de julio de $1787=$ ultimo tachado no vale $=$ las oficinas duplicado no vale.

Ignacio de Castera

[Rúbrica] 
A.H.C.M.: Manzana de la Diputación, vol. 1087, exp. 17, pp. 9-10-11.

\section{DOCUMENTO IV}

"Nos el Doctor Don Alonso Nuñez de Haro y Peralta, por gracia de Dios, y de la Santa Sede Apostólica, Arzobispo de México, del Consejo de Su Magestad".

"Por quanto en Representacion que Antes Nos hizo el Ilustre Ayuntamiento de esta Novilisima Ciudad, expuso que teniendo en su Sala Capitular, una Capilla, cuya facultad y Privilegio, que no se havian podido encontrar en sus Archivos, habrian regularmente perecido en el Yncendio acaecido en el año de noventa y dos, del siglo pasado, en cuia atención y consultando a su maior seguridad de conciencia, había acordado pedirnos, y suplicarnos, le concediesemos la licencia necesaria para continuar en dicha gracia; por tanto, haviendo consideración por los expresados, y en el supuesto y satisfaccion de que la enunciada Capilla, estava decente y abundantemente provista de Basos sagrados y demás utensilios correspondientes al culto del Señor: Por el tenor de la presente, se la damos, y concedemos porque que por qualquiera Sacerdote Secular o Regular, aprovado en nuestro Arzobispado, pueda celebrarse sin perjuicio del Derecho Parroquial el Santo Sacrificio de la Misa, todos los días del año, aun en los prohividos por derecho, excepto el Jueves, Viernes y Sabado de la Semana Santa, Y declaramos que cumplen con el presepto de Nuestra Santa Madre Iglesia, todos y qualesquiera Personas sin excepción de alguna, que con la Atención, y reberencia devida asistieren al Santo Sacrificio en la indicada Capilla, que deberá reputarse por publico; y Sujetamos a nuestra Santa Visita, a la de nuestro Ilustrisimos Señores Subcecretarios Visitadores y en sede-vacante a la del nuestro Ilustre y Venerable Señor Dean, y Cavildo de Nuestra Santa Iglesia Cathedral Metropolitana en virtud de esta licencia que balga por el tiempo de nuetra Voluntad. Dada en nuestro Palacio Arzobispal de la Villa de Tacubaya, firmada de Nos sellada con el sello de Nuestras Armas, y refrendada dei Ynfrascipto nuestro Secretario de Camara y Govierno, a veinte dias del mes de mayo de mil setecientos noventa y un años = Alonso Aizobispo de México $=$ Lugar del sello = Por "Mandato de su Ecxelencia, el Arzobispo, mi señor = Doctor Don Manuel Flores, Secretario".

A.H.G.M.: Manzana de la Diputación, vol. 1087, exp. 3, p. 10. Transcripción paleográfica de Jorge Nacif Mina. 


\section{DOCUMENTO V}

En la ciudad de México à los diez y seis diaz del més de enero de mil ochocientos noventa y tres, presentes en la Sala de comisiones del Ayuntamiento los Regidores de la Junta de Hacienda que suscriben el Señor Charles B. Brisbin por la Compañía de Mármoles Mexicanos, sociedad anónima y el Señor Gabriel Guerra por su propio derecho, con el objeto de formalizar el contrato que celebraron con el Ayuntamiento el nueve de Diciembre último que fué aprobado por la Corporación el veinte y sancionado por la superioridad el veintisiete el mismo, para ejecutar las obras de marmol y bronce para el ornato de la Sala de Cabildos, han convenido en verificarlo bajo las bases siguientes.

Primera: La Compañía de mármoles se obliga á ejecutar en la Sala de Cabildos las obras que le han sido indicadas por las comisiones de Hacienda y Obras públicas bajo estas condiciones:

A Las obras deberán tener la figura y dimensiones que demuestra el dibujo presentado por el Señor escultor Don Gabriel Guerra.

B El zócalo será de marmol gris del pais, lambrin, chambranas y cornisas de marmol "tennessee" de los colores que marca el dibujo.

Segunda: La comisión de Obras públicas ministrará el tabique y cemento necesarios para la ejecución de las obras.

Tercera: Las obras de que se trata deberán estar concluidas antes del quince de Marzo del año actual salvo un caso fortuito ó de fuerza mayor debidamente comprobado.

Cuarto: El Ayuntamiento se obliga á pagar la Compañía de Mármoles mexicanos, sociedad anónima, en esta ciudad y en pesos fuertes del erario mexicano como precio de la obra, la suma de doce mil pesos $\$ 12,000$. Este pago lo hará en ambos de mil pesos mensuales, haciendo la primera exhibición en el presente més

Quinta: El Señor Don Gabriel Guerra por su parte se obliga á ejecutar las obras de bronce à que se refiere sus presupuesto fecha de nueve del més proximo pasado que se acompaña: por la suma de dos mil doscientos pesos $\$ 2,200$, debiendo terminarlas también para antes del quince del citado Marzo.

Sexta: La expresada cantidad será pagada al Señor Guerra en partidas de quinientos pesos mensuales á contar desde el més en curso.

Séptima: Las estampillas del timbre que debe llevar este documento para su validez legal, serán pagadas entre las partes contratantes.

Leidas las anteriores bases y estando conformes los interesados con su contenido, firman para constancia.

$\begin{array}{ccc}\text { Gabriel Guerra } & \text { Eduardo Rincon Gallardo } & \text { C.B. Brisbin } \\ \text { [Rúbrica] } & \text { [Rúbrica] } & \text { [Rúbrica] }\end{array}$

A.H.C.M.: Manzana de la Diputación, vol. 1088, exp. 71. 


\title{
DOCUMENTO VI
}

C. Presidente y regidores del Honorable Ayuntamiento de Mexico

Gabriel Guerra ante esa corporación respetuosamente expone, que encontrandome enfermo no me es posible concurrir personalmente à las oficinas de ese ilustre cuerpo à liquidar la cuenta relativa à las obras de decoracion del Plafon del Salón de Cabildos del Palacio Municipal que contraté, y à recibir el pago del saldo que alcanzo. Como ademas esos saldos ya no me corresponden pues en virtud de una asociacion particular en participación que celebré con el Señor Felix Parra, y de la liquidacion que con el he practicado resulta que à el corresponden como alcances á la remuneracion de su trabajo todo el saldo que aparesca personalmente á mi favor en la cuenta de Decoracion del Plafon, ocurro á esa corporacion manifestandole este hecho y suplicandole se sirva tener como verdadero y unico acredor de dicha cuenta y competentemente autorizado para liquidarla y percibir el saldo respectivo al expresado Señor Felix Parra á quien si fuere necesario cedo y traspaso en toda forma mis derechos y confiero las facultades para dicha liquidacion y cobro.

Por tanto

Al Honorable Ayuntamiento suplico se sirva ácordar la liquidacion y pago de la cuenta mencionada en el expresado Señor Felix Parra

Mexico Octubre 6 de 1893

\author{
Gabriel Guerra \\ [Rúbrica]
}

Otro Si suplico a Usted se sirva hacer que el Escribano de diligencias pase à mi casa à reconocer mi firma por estar yo imposibilitado para ir y entregar personalmente esta solicitud.

\section{Gabriel Guerra \\ [Rúbrica]}

A.H.G.M.: Manzana de la Diputación, vol. 1088, exp. 71.

\section{DOCUMENTO VII}

Considerando que es conveniente que el Palacio Municipal sea destinado exclusivamente á las oficinas del Ayuntamiento y que en cuanto sea posible todas esas oficinas quedan concentradas en un solo edificio, tengo la honra de someter 
á la Comisión de Hacienda para que si las encuentra acertadas se sirva honrarlas con su voto y someterlas á la aprobación del Cabildo, las siguientes proposiciones:

1a. La Dirección de Obras públicas procederá à formar un proyecto de distribución del Palacio Municipal comprendiendo la parte de los bajos que actualmente está arrendada para establecimiento de comercio.

2a La Dirección presentará dicho proyecto á la aprobación del Ayuntamiento antes del 31 de Agosto próximo.

3a. Aprobado el proyecto por el Ayuntamiento, no podrá variarse la distribución del Palacio Municipal ni ejecutarse en él obra alguna que no esté conforme al mismo proyecto, sin prévio acuerdo del Cabildo

4a. No se celebrará en lo sucesivo ningun contrato de arrendamiento de locales en el Palacio Municipal ni se prorrogará contrato alguno de los que estan en vigor por términos que exceda del 15 de Abril de 1900 para los locales que quedan al Poniente de la entrada principal, ni del 31 de Agosto de 1902 para los que quedan al Oriente de la misma entrada.

Sala de Comisiones. Mayo 12 de 1898.

\section{Miguel S. Macedo.}

[Rúbrica]

A.H.C.M. Manzana de la Diputación, vol. 1090, exp. 143, pp. 1-2 